\title{
Case Report on Crossed Ectopia Testis
}

\author{
Dr.NikhileshKundu *,Dr.HariIgniusPandey **
}

\begin{abstract}
Undescended testes can be found in the inguinal canal or in the abdomen. Rarely, undescended testes can present with transverse testicular ectopia (TTE). Crossed testicular ectopia or transverse testicular ectopia is a rare entity.About a little more than 100 cases are reported in literature. It is one of the well-known congenital anomalies, in which both gonads migrate toward the same hemiscrotum, usually associated with some other abnormalities such as persistent Mullerian duct syndrome (PMDS), true hermaphroditism, inguinal hernia, hypospadias, pseudohermaphroditism, and scrotal anomalies. We report a case of transverse testicular ectopia in an23-months-old boy who presented with right inguinal hernia and nonpalpable left testis. On ultrasound it was reported as both the testicles are in a unified sac near the right inguinal region at the deep ring. On exploration, both testes were present in the right inguinal region. Bilateral orchiopexy was performed by crossing the left testis in the extra-peritoneal space and ipsilateral scrotal orchiopexy. The diagnosis could not be made preoperatively in most of reported cases.
\end{abstract}

Keywords: testis, undescended testis, cryptorchidism, testicular ectopia

\section{Case presentation}

The patient was a 23 months old boy, who admitted for nonpalpable testis both sides and right inguinal hernia. The patient was born with normal vaginal delivery, with a normal Apgar score. There was no history of illnesses or poor feeding or failure to thrive (FTT). General physical examination was unremarkable. Hematological examination and biochemistry lab data was normal. In external genitalia examination, the right testis was palpable inguinallyat the deep ring with an evident hernia and the left hemiscrotum was empty.Ultrasonography was done showed both the testis are seen in a unified scrotal sac at the level of deep ring on right side with small dilated right inguinal hernia. The patient was posted for synchronous bilateral orchiopexy and right inguinal herniotomy. Firstly, right inguinal incision was given. The right testis with its overlying tunica vaginalis was found at the deep inguinal ring and after opening of the tunica, the fluid inside of it drained and the testis was found. At the proximal part of the cord another testis was found (Figure 1 (Fig. 1)). After releasing of cords and dissection of the hernia sac bilateral orchiopexy were done. Two cords were found separate for about 5 to $6 \mathrm{~cm}$. Finally, the left testis was transferred with its cord to the left hemiscrotum easily and extra-peritoneally. Both testes were fixed in the sub-dartos pouch.

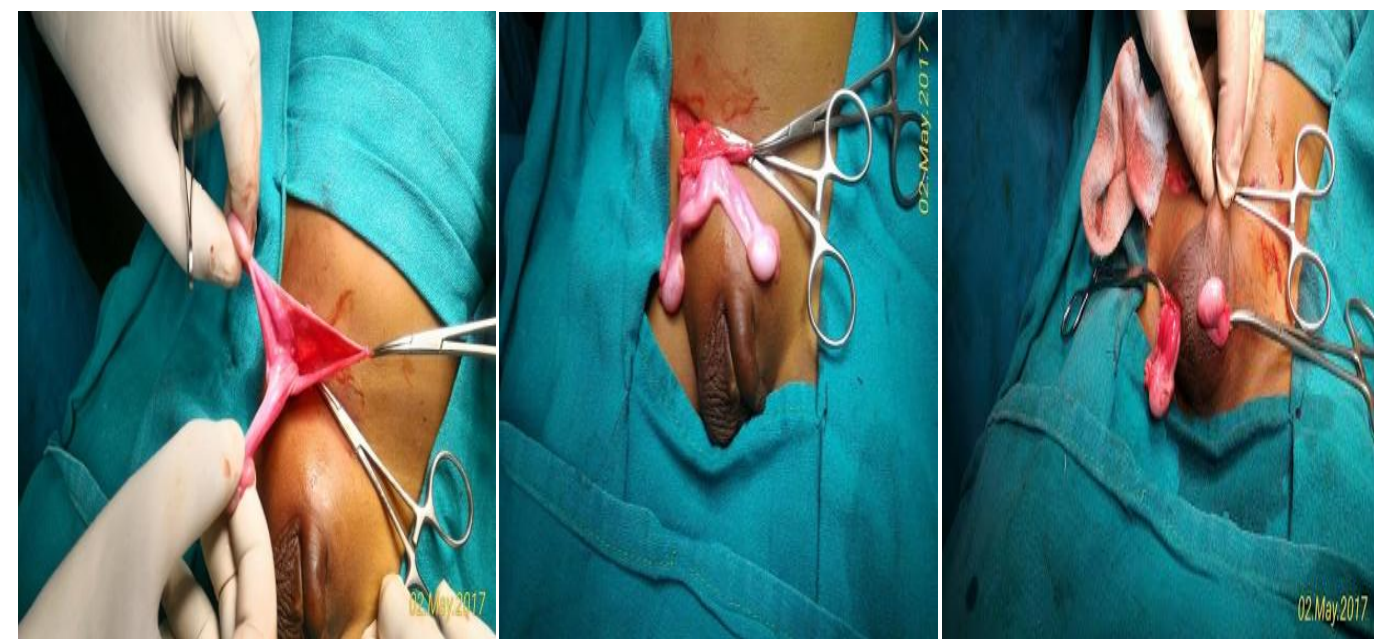

Fig 01 both testis seen in single sac Fig 02 the cords are separate. Fig 03 bilateral orchiopexy

\section{Discussion}

Crossed testicular ectopia is a rare form of testicular ectopia. It was first reported by Von Lenhossek in 1886. More than 100 cases have been reported in the literature. Several theories have been reported to explain the genesis of TTE. Berg proposed the possibility of the development of both testes from the same genital ridge. Kimura concluded that if both vasa deferentia arose from one side, there had been unilateral origin but if there 
was bilateral origin, one testis had crossed over. Gupta and Das postulated that adherence and fusion of the developing Wolffian ducts took place early, and that descent of one testis caused the second one to follow.

It is also named testicular pseudoduplication, unilateral double testis, and transverse aberrant testicular maldescent. On the basis of the presence of various associated anomalies, TTE has been classified into 3 types: Type 1, accompanied only by hernia ( $40 \%$ to $50 \%$ ); type 2 , accompanied by persistent or rudimentary Mullerian duct structures (30\%); and type 3, associated with disorders other than persistent Mullerian remnants (inguinal hernia, hypospadias, pseudohermaphroditism, and scrotal abnormalities) (20\%). According to that classification, our case was type 1 TTE. TTE associated with fused vas deferens is extremely rare. This condition may hinder the testis from being placed into the scrotum during orchiopexy. An inguinal hernia is invariably present on the side to which the ectopic testis has migrated.

Once diagnosis of TTE is made by clinical examination and supported by ultrasound findings, a conservative surgical approach in the form of orchiopexy is recommended for the preservation of fertility . Laparoscopy is useful for both diagnosis and treatment of TTE and associated anomalies. Management for testicular ectopia is either trans-septal or extra-peritoneal transposition orchiopexyand a search for Mullerian remnants and other anomalies, and long-term postoperative follow-up. There were two options for left orchiopexy in our case: extra-peritoneal orchiopexy and trans-septalorchiopexy. In the extra-peritoneal technique the testis is brought to the contra-lateral hemiscrotum after its passing near the root of penis. In the trans-septal technique the testis should traverse the scrotal mediastinum to be fixed in it. In the case of fused vas deferens, unlike our case, a trans-septalorchiopexy is recommended. It may be misdiagnosed as an inguinal hernia and intersex or present as an irreducible hernia, requiring urgent surgery .

\section{Conclusion}

In conclusion, TTE is a rare condition and should be suspected in patients presenting with inguinal hernia on one side and cryptorchidism on the other side. As PMDS and TTE are usually discovered incidentally during surgery for undescended testis or inguinal hernia, the optimal surgical approach should include testicular biopsies, herniotomy, orchidopexy and excision of MD remnants without risking the vas deferens. A long-term follow-up will be needed for assessment of the fertility in these patients.

\section{References}

[1]. Von Lenhossek MN. Ectopia testis transversa.AnatAnz. 1886;1:376-381.

[2]. Fourcroy JL, Belman AB. Transverse testicular ectopia with persistent Müllerian duct. Urology. 1982;19(5):536-538. doi: 10.1016/0090-4295(82)90614-8. Available from: http://dx.doi.org/10.1016/0090-4295(82)90614-8. [PubMed] [Cross Ref]

[3]. Berg AA. Transverse ectopy of the testis. Ann Surg. 1904;40:223-224. [PMC free article] [PubMed]

[4]. Kimura T. Transverse ectopy of the testis with masculine uterus. Ann Surg. 1918;68(4):420-425. doi: 10.1097/00000658191810000-00009. Available from: http://dx.doi.org/10.1097/00000658-191810000-00009. [PMC free article] [PubMed] [Cross Ref]

[5]. Gupta RL, Das P. Ectopia testis transversa. J Indian Med Assoc. 1960;16:35:547-549. [PubMed]

[6]. Chacko JK, Furness PD, 3rd, Mingin GC. Presentation of fused vas deferens.Urology. 2006;67(5):1085.e17-1085.e18. doi: 10.1016/j.urology.2005.11.056. Available from: http://dx.doi.org/10.1016/j.urology.2005.11.056. [PubMed] [Cross Ref]

[7]. FeizzadehKerigh B, MohamadzadehRezaei M. Crossed testicular ectopia: a case report. Urol J. 2005;2(4):222-223. Available from: http://www.urologyjournal.org/index.php/uj/article/view/229/226. [PubMed]

[8]. Acikalin MF, Pasaoglu O, Tokar B, Ilgici D, Ilhan H. Persistent Mullerian duct syndrome with transverse testicular ectopia: a case report with literature review. Turk J Med Sci. 2004;34:333-336.

[9]. Nam YS, Baik HK, Kim SJ, Lee HK, Park HK. Transverse testicular ectopia found by preoperative ultrasonography. J Korean Med Sci. 1998;13(3):328-330. [PMC free article] [PubMed]

[10]. Berkmen F. Persistent müllerian duct syndrome with or without transverse testicular ectopia and testis tumours. Br $\mathrm{J}$ Urol. 1997;79(1):122-126. [PubMed]

[11]. Melman A, Leiter E, Perez JM, Driscoll D, Palmer C. The influence of neonatal orchiopexy upon the testis in persistent Müllerian duct syndrome. J Urol. 1981;125(6):856-858. [PubMed]

[12]. Eastham JA, McEvoy K, Sullivan R, Chandrasoma P. A case of simultaneous bilateral nonseminomatous testicular tumors in persistent müllerian duct syndrome. J Urol. 1992;148(2 Pt 1:407-408. [PubMed]

[13]. Walsh TJ, Dall'Era MA, Croughan MS, Carroll PR, Turek PJ.Prepubertalorchiopexy for cryptorchidism may be associated with lower risk of testicular cancer. J Urol. 2007;178(4 Pt 1):1440-1446. doi: 10.1016/j.juro.2007.05.166. Available from: http://dx.doi.org/10.1016/j.juro.2007.05.166. [PubMed] [Cross Ref]

[14]. Wood HM, Elder JS. Cryptorchidism and testicular cancer: separating fact from fiction. J Urol. 2009;181(2):452-461. doi: 10.1016/j.juro.2008.10.074. Available from: http://dx.doi.org/10.1016/j.juro.2008.10.074. [PubMed] [Cross Ref]

[15]. Tolete-Velcek F, Bernstein MO, Hansbrough F. Crossed testicular ectopia with bilateral duplication of the vasa deferentia: an unusual finding in cryptorchism. J Pediatr Surg. 1988;23(7):641-643. doi: 10.1016/S0022-3468(88)80636-5. Available from: http://dx.doi.org/10.1016/S0022-3468(88)80636-5. [PubMed] [Cross Ref]

[16]. Gornall PG, Pender DJ. Crossed testicular ectopia detected by laparoscopy. Br J Urol. 1987;59(3):283. doi: 10.1111/j.1464410X.1987.tb04627.x. Available from: http://dx.doi.org/10.1111/j.1464-410X.1987.tb04627.x. [PubMed] [Cross Ref]

[17]. Esteves E, Pinus J, Maranhão RF, AbibSde C, Pinus J. Crossed testicular ectopia. Sao Paulo Med J. 1995;113(4):935-940. [PubMed]

[18]. Pandey A, Gupta DK, Gangopadhyay AN, Sharma SP. Misdiagnosed transverse testicular ectopia: a rare entity. Hernia. 2009;13(3):305-307. doi: 10.1007/s10029-008-0434-5. Available from: http://dx.doi.org/10.1007/s10029-008-0434-5. [PubMed] [Cross Ref] 
[19]. Vaos G, Zavras N. Irreducible inguinal hernia due to crossed testicular ectopia in an infant. Hernia. 2004;8(4):397-398. doi: 10.1007/s10029-004-0232-7. Available from: http://dx.doi.org/10.1007/s10029-004-0232-7. [PubMed] [Cross Ref]

[20]. Barrack S. Crossed testicular ectopia with fused bilateral duplication of the vasa deferential: an unusual finding in cryptochidism. East Afr Med J. 1994;71(6):398-400. [PubMed]

[21]. Articles from GMS German Medical Science are provided here courtesy of German Medical Science

[22]. *Consultant, Dept of surgery, Tata Main Hospital, Jamshedpur. nikhileshkundu@ gmail.com

[23]. ** Head Consultant, Dept of surgery, Tata Main Hospital, Jamshedpur. 